\title{
FEATURES OF ACCOUNTING FOR FINANCING AGRICULTURAL PRODUCERS
}

\author{
Y. Andreev* \\ Department of Economics, Faculty of Economics, Trakia University, Stara Zagora, Bulgaria
}

\begin{abstract}
Market transformations and developments over the last decade in the Bulgarian economy have mainly affected the financing system for the agrarian sector. The formation and development of financial and credit relations in rural areas has revived the processes of credit cooperation between farmers. The market environment sets out the general rules for the production and exchange of goods and services: it depends on the costing framework and the choice of how they are organized. In essence, agri-industry producers act primarily as consumers of financial and credit institutions, which on the one hand attract temporary free funds to shareholders and other financial institutions; on the other hand, they meet the different financial needs of the members of the farmers with these funds raised. The study of the theoretical and practical features of reporting to farmers in the agrarian sector shows that this is a little studied area. It is mainly in almost complete isolation from the realities of the market economy, which puts new tasks for financial co-operation. The inadequacy of accounting in the agrarian sector is becoming more obvious with the entry of Bulgaria into the European Union and the common agricultural policy.
\end{abstract}

Key words: agrarian sector, finance, agriculture, accounting

\section{INTRODUCTION}

Due to differences in the nature of business activity of agricultural producers there are certain specifics into the accounting. These features are mainly associated with the initial and current valuation of assets produced in the agricultural sector, in contrast to other enterprises operating in our national economy. The features are described in national accounting standard 41 , which states that "the activities by which biological assets and their biological transformation in agricultural products are managed in order to be sold, processed or used in this activity." This quote reflects the very nature and characteristics of agricultural production.(1)

The purpose of the article is to describe some features of accounting for financing enterprises in the agricultural sector. It shall help counsel accountants an managers of agricultural

\footnotetext{
*Correspondence to: Yanislav Andreev, PhD student,Department of Economics, Faculty of Economics, Trakia University, Stara Zagora, Bulga ria, Post code: 6000, janislav_andreev@abv.bg
}

enterprises to be able to organize the accounting of their activity in the best possible way.

The agricultural sector, in general, is divided into two main subsectors: crop production and animal husbandry. The reporting of accounting for these two branches of agriculture is very similar and is described in the same accounting standard (AS) 41 as described above. In addition, the International Accounting Standard (IAS) 41 "Agriculture" and our national accounting standard (NAS) overlap. Below we consider the main features of accounting for agricultural producers and focus mainly on accounting for financial aspects of business activities.

\section{FEATURES OF ACCOUNTING FOR AGRICULTURAL PRODUCERS}

The first and most important feature is the discrepancy between the accounting and business year. This is due to seasonal business activity. Therefore, the "Law of land lease" states the following: "the working year is the period from October $1^{\text {st }}$ of the current year to 
October $1^{\text {st }}$ of the next year"'(2), whereas in the accounting year the "Law on Accounting" records that this period is from January $1^{\text {st }}$ to $31^{\text {st }}$ December or one calendar year.(3) This is an extremely important peculiarity, which plays an extremely important role in reporting on financial transactions, receiving and spending subsidies, and also in reporting on financial results. Care must be taken to account for all transactions, since they relate to one working year, but some of them are reported in the previous calendar year and others in the current calendar year.

Another important feature that plays a key role in reporting is associated with the changes that occur to biological assets as a result of their growth. This is due to difficulties in transferring animals from one herd to another, depending on age or weight. This also applies to factory production, where there are different stages of production maturity. There is an inherent difficulty to explain this process, because an accountant in most of the cases does not take into account the biological nature of assets, but considers them ordinary. In such cases, there is a risk of inaccuracies and errors in the record, so it is useful for the accountant to get acquainted by the agricultural producers with the characteristics of the plants they are growing or animals they breeding.

The next important feature that has a serious impact upon the production activity of the activity is associated with the influence of natural and climatic conditions. There are various natural disasters that increase the likelihood of loss and reduction of financial results. This feature applies mainly to crop production, since the most common areas are in the open air. Adverse factors are mainly related to natural disasters, such as: flood, drought, hail, tornado, frost, etc. Of course, there is a possibility that these adverse climatic conditions may also affect livestock. This is mainly due to the supply of food on the farm, especially when the production cycle is closed.

An important feature is the diversification of agriculture. It has two aspects that are directly related to the reduction of negative impacts caused by various natural factors, and the preservation of financial results. The first aspect of diversification is associated with the sowing of different annual crops in the current calendar year. This is done in order to avoid adverse conditions that may affect some cultures. For example, one oat can be planted on the same area, and after harvesting corn for sowing. Thus, the farm can provide feed for the farm, and in adverse climatic conditions it can rely on at least one of the crops. Another aspect of diversification is associated with the cultivation of the same type of crops or animal species, but localized in different places. This means that an agricultural producer sows plots with the same crop, but in different parts of the land on which he is located. Thus, in the event of flooding or hail on parts of the land, these adverse conditions are expected to affect only one of the areas visited. In the same way, a farmer can have several small storages that are far from each other in order to avoid transmission of diseases. This type of diversification reduces indeed the risk of losses caused by various adverse factors, but, on the other hand, increases the cost and reduces the likelihood of achieving economies of scale. This measure, of course, greatly complicates the accounting reporting, as the number of objects increases and requires additional work.

The last important feature that has to be considered is the receipt of subsidies. This feature is extremely important for the development of agriculture. Since the inclusion of Bulgaria to the EU, access to subsidies for agricultural producers has increased many times. In addition to subsidies from various EU structural funds, our country provides grants to agricultural enterprises through the State Fund for Agriculture. When an agricultural producer receives financial assistance from the EU or Bulgarian government, a problem arises that is directly related to the recognition of income from subsidies. The problem is mainly due to the fact that there are big discrepancies in the texts of IAS and NAS, which regulate subsidy reporting.(4)

Regarding International Accounting Standard 20, which deals with accounting for government grants provided to agricultural producers. The standard states that "government subsidies are recognized as revenue for the periods necessary to compare them with the associated costs, which are intended to compensate using a systematic basis."(5). On the other hand, the national accounting standard (NAS) 20, according to which "government subsidies received by enterprises as compensation for past expenses or losses are recognized as income for the period they are received"(6). These two standards are very different, because depending on which standard is used to report 
on grants, there will be obtained a difference in the annual financial statements. Therefore, when organization choose their accounting policies, it is extremely important to pay serious attention to which accounting standards will be applied.

\section{OPPORTUNITIES FOR IMPROVING REPORTING ON FINANCING AGRICULTURAL PRODUCERS}

These features in accounting for various financial transactions in agriculture can significantly affect the accuracy of information obtained from basic accounting records. Here the role of an accountant is extremely important. He must choose the method by which he will take into account the financing of the enterprise for which he is responsible. Therefore, here we will try to present the two main methods of reflecting the financing of companies in the agricultural sector.

In the case of European or governmental unconditional financing in the form of a financial instrument, biological and fixed assets should be taken into account only after receiving funding. After receiving donations in the form of long-term and biological assets, they must be estimated at a fair market price, and then deducted from the expected value of their sale. When donations take the form of long-term and biological assets, there are no problems in reporting. The main difficulty lies in the accounting of funds received from European funds and from the State Fund for Agriculture. These funds are not described in Art. 26 of the Law on VAT and, therefore, should not be subjected to VAT.(4)

As stated above, there are two accounting standards, one national and one international, that govern reporting subsidies received. Both methods are quite compromised using the NAS 20 mentioned. The problem is mainly related to subsidizing larger farms, which receive huge subsidies from the state budget and European funds. Then proceeding into accounting using the cash basis, the accountant reports only about the moment state of their income, which may lead to distortion of information in the annual financial statements. On the other hand, the Law on Corporate Tax does not specify how to achieve specific taxation. Therefore, in many agricultural enterprises, subsidies are recognized as revenue for tax purposes and participate in the formation of the tax financial result for the calendar year in which they were received.
For correct accounting information, taking into account the subsidies received, paragraph 3.2 (b) of accounting standard (AS) 20 should be applied in the following sequence.(6)

Example: a farmer receives a donation of 20 levs per are and processes a total of 2000 ares, receiving a total of 40,000 levs. These funds should be accounted for as follows:

Debt account Cash 40000

Credit Account Funding 40,000

This is done at the request of the aforementioned AS20, because the financing is a non-depreciable asset, and it is a question of reporting for the period during which the expenses for fulfilling the donation conditions were accrued.

Following operations should be reported ahead.

Debt account Funding for current business 40 000

Credit Account Revenues from funded 40,000 and

Debt account Revenues from funded 40,000

Credit Account Operating expenses 40000

Many accounting researchers have addressed the issue of subsidy reporting over the past decade. Subsidies received by agricultural producers to cover the cost are direct payments. For this reason, this income must be indicated in the year when the relevant expenses were incurred, and not in the year when funding was received. Here an important question arises: "When is this income recognized?", because one method can be taken into account in the year of receipt, and the other in the year of expenses incurred. In this case, the answer must be unambiguous and not receive discrepancies in the information of the annual financial statements of the agricultural enterprise.

The most reasonable solution, according to the author, is that subsidies should be reported in the year for which they were received. Because these funds are allocated for the year in which the cost of the activity is produced. Therefore, if funding is taken into account not for the year to which it relates, but for the report for the year of incur, then the AS 8 rules should be used, which also offer two reporting methods.(7) The first method is recommended and refers to the results of the period covered by the payment. Another method is an alternative to reporting in the current period, 
but by compiling a second annual financial report to reflect the error.

From the above, attention should be paid to the fact that financing is a type of claim, which means that we can consider it as other receivables of an enterprise. In this case, when subsidies are received at the beginning of the next year, they should remain in the balance sheet, while revenue should be reflected in the past reporting year, as it relates to it.(4)

\section{CONCLUSION}

The article introduces the features of accounting reporting of the activity of agricultural producers, paying particular attention to the financing of enterprises. Therefore, in the second part of the article, we monitored the possibilities of accounting, tax regime and improving the financing of agricultural enterprises. Particular attention was paid to international and national accounting standards that directly affect the accounting reporting of subsidies in the agricultural sector. It became clear from the survey when and how to recognize revenue from financing in order to ensure the accuracy of the annual financial statements.

The author is grateful to the National Science Program "Healthy Foods for a Strong BioEconomy and Quality of Life", FP 4.3. A new generation of value-added bio-based chains, funded by the Ministry of Education and Science.

\section{REFERENCES}

1. National accounting standard 41 Agriculture.

2. Law on the lease of agricultural land.

3. Law on Accounting.

4. Georgieva, E. Legal regulations in support of the agricultural producers in Bulgaria. Plovdiv, Scientifics works, vol. LVI, 2012, Academic Publishing House of Agricultural University Plovdiv, ISSN 1312-6318-4, p.227-232.

5. Rupska T., "Applied aspects and problems of management accounting in the agricultural sector when Bulgaria joined the European Union", UP "Holding", Sofia, 2011
6. Georgieva, E. Options for reporting of depreciation of fixed biological assets according to IAS 41 Agriculture. Electronic journal "Economics and computer science", Volume 2, 2016, ISSN 2367-7791, Varna, Bulgaria, p.15-22.

7. Georgieva, E., Penev, N. Accounting for the depreciation of the vineyards and its impact on the taxation of the enterprise, International scientific-practical conference "Possibilities for business development economic, management and social dimensions", Svishtov, 2018, v. 1, ISBN 978-954-23-1702-9, p.351-358.

8. International Accounting Standard 20 "Accounting for government grants and disclosure of information on government assistance."

9. Georgieva, E. Penev, N. Accounting opportunities for depreciation of a cow herd. Trakia Journal of Sciences, ISSN 1313-7069/ Volume 15, 2017. Series Social Sciences/p. 223-228.

10.National accounting standard 20 Reporting on government subsidies and disclosure of information on government assistance.

11.Accounting standard 8 - Net gains or losses for the period, fundamental errors and changes in accounting policies.

12.Nenova, R., Agricultural holdings - a new manifestation of social agriculture, Dimitar A. Tsenov Academy of Economics Svishtov, Narodnostopanski Archives, 2014, pp 55-70.

13.Nenova, R., Monitoring of agricultural greenhouse gases, Dimitar A. Tsenov Academy of Economics - Svishtov, Narodnostopanski Archives, 2015, pp 7090.

14.Perkov, V., Classification of European countries by the level of business-tobusiness e-commerce development, Dimitar A. Tsenov Academy of Economics Svishtov, Yearbook, 2016, pp 241-277.

15.Nenova, R., Methodological differences in the environmental footprint, Dimitar A. Tsenov Academy of Economics - Svishtov, Almanac scientific research, Vol. 24, 2017, Part II., pp 179-205. 